\title{
Thermal metamorphism of the Mócs meteorite (L6) revealed by optical microscopy and BSE imaging
}

\author{
Ildikó Gyollai ${ }^{1,2,3}$, Szaniszló Bérczi ${ }^{1}$, Krisztián Fintor ${ }^{4}$, Szabolcs Nagy ${ }^{4}$, \\ Arnold Gucsik ${ }^{5,6 *}$
}

\begin{abstract}
${ }^{1}$ Department of Material Physics, Institute of Physics, Eötvös Loránd University, Budapest, Hungary ${ }^{2}$ Impact Research Group, Department of Lithospheric Research, University of Vienna, Vienna, Austria ${ }^{3}$ Geobiomineralization and Astrobiology Research Group, Research Centre for Astronomy and Earth Science, Institute for Geological and Geochemical Research, Hungarian Academy of Sciences, Budapest, Hungary

${ }^{4}$ Department of Mineralogy, Petrology and Geochemistry, University of Szeged, Szeged, Hungary ${ }^{5}$ Department of Geology, University of Johannesburg, Johannesburg, South Africa ${ }^{6}$ Research Centre for Astronomy and Earth Sciences, Konkoly Thege Miklós Astronomical Institute, Budapest, Hungary
\end{abstract}

Received: March 5, 2015; accepted: October 29, 2015

The Mócs chondrite was studied by optical microscopy, element mapping, as well as scanning electron microscope backscattered electron (SEM-BSE) imaging, in order to gain a better understanding of the thermal metamorphic as well as post-shock annealing evolution and the mineralogical signatures in this meteorite. The studied thin section of Mócs meteorite contains 26 chondrules with a variety of chondrule textures, which are characterized by a blurry rim. The chondrules mostly consist of pyroxene and olivine, whereas feldspars occur only in the recrystallized groundmass, chondrule mesostasis, and mineral melt inside and beyond the shock veins. It was found that the matrix was completely recrystallized. According to the scanning electron microscope and optical microscope observations mentioned above, it can be concluded that the Mócs chondrite is a 6.5 petrographic type.

Keywords: Mócs meteorite, L-chondrite, thermal metamorphism, chondrule textures, petrography

\section{Introduction}

The Mócs is an L6-type ordinary chondrite, which was observed to fall in Kolozs County (Hungary) in 1882 (Ferko et al. 2000); it broke into as many as 3000 pieces, thus being among the most dense showers in the world. Other dense historical falls of L chondrites were geologically identified, also with numerous

*Corresponding author: Arnold Gucsik; Konkoly-Thege Miklós út 15-17, H-1121 Budapest, Hungary

E-mail: gucsik@mailmax.hu 
fragments, such as an extensive shower in the Ordovician (Greenwood et al. 2007). The chemical composition of the Mócs-01 thin section was determined by Electron Microprobe Analyses (EMPA; Kubovics et al. 1997, 2004) and was found to be a heavily shocked meteorite containing well-developed shock veins. The mineral assemblage of the Mócs meteorite consists of olivine, pyroxene, albitic feldspars, and opaque minerals.

The first process to occur after chondritic parent body formation was that of thermal metamorphism. The thermal metamorphic evolution of a chondritic parent body has been described by van Schmus and Wood (1967) on the basis of textural and chemical alteration. Slow thermal metamorphism was caused by solid state diffusion, which rearranged the texture significantly. The most prominent effects of diffusion are blurring of chondrule rims, the homogenization of mineral compositions, change of metallic iron to oxidized iron ratio by redox processes, and gradual recrystallization. In parallel with thermal metamorphism, impacts caused shock metamorphism, which produced shock-veins. This was followed by postshock thermal metamorphism, which transformed a relatively small part of the parent body.

As earlier investigators asserted (e.g. Bérczi et al. 2004), L chondrites are heavily shocked (Xie et al. 2000). Due to their heavily shocked character they are thought to have originated from the putative disruption of an asteroid (Nesvorný et al. 2009). The disruption time (470 Ma) is in good agreement with that of the Ordovician L chondrite shower (467 Ma; Haack et al. 1996; Korochantseva et al. 2007). An onion-type L-asteroid has been suggested as the initial host, with outer normal layering of L3, L4, L5 and L6 layers from top down (Bérczi 2000; Bérczi et al. 2004; Fig. 1). At this time the parent body/bodies for the L group chondrites has not been identified, but plausible suggestions include 433 Eros and 8 Flora, or the Flora family as a whole (Haack et al. 1996; Nesvorný et al. 2002). The reflec-

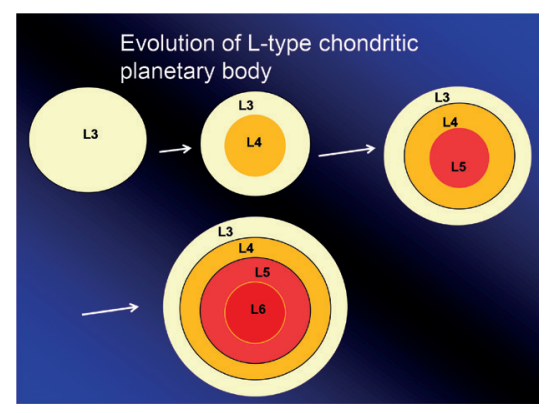

Fig. 1

Thermal metamorphic evolution of L-type chondritic planetary body - onion-layer model (after Bérczi 2000) tance spectrum of $\mathrm{L}$ chondrites has similarities with that of 433 Eros, while several pieces of these chondrites show evidence of relationship with the Flora family as follows: (1) the Flora family is thought to have formed about 1,000 to 500 million years ago; (2) the Flora family lies in a region of the asteroid belt that contributes strongly to the meteorite flux to Earth; (3) the Flora family consists of S-type asteroids, whose composition is similar to that of chondrite meteorites; and (4) the Flora family parent body was over 100 kilometers (62 mi) in diameter (Nesvorný et al. 2002). 


\section{Samples and Experimental Procedure}

The thin section was mounted in epoxy and its thickness was polished down with $\mathrm{A}^{12} \mathrm{O}^{3}$ to approximately $35 \mu \mathrm{m}$. The mineral assemblages and textures were characterized with a Nikon Eclipse LV100POL optical microscope (under $\times 40-\times 1000$ magnification, in transmitted and polarized light, etc.) at Eötvös University, Department of Petrology and Geochemistry, Budapest, Hungary.

The polished Mócs-01 thin section was coated with carbon in a JEOL JEE4B vacuum evaporator for scanning electron microscopy (SEM), energy-dispersive X-ray spectrometry (EDX) and back scattered imaging (BSE), at the Department of Petrology and Geochemistry, Eötvös University (Budapest, Hungary). The minerals were determined with BSE and EDX detectors of an Amray 1830 IT/6 electron microscope with EDAX PV9800 EDS detector, a beam current of $1 \mathrm{nA}$ and a defocused spot size of $10-50 \mu \mathrm{m}$; collection time $100 \mathrm{~s}$. The acceleration voltage was $20 \mathrm{kV}$. The imaging was done by TESCAN Satellite TS1130 software running on a Windows XP system. The detection limit of the EDS detector is $0.1 \mathrm{wt} \%$; hence major constituents of adjacent minerals could be measured, but trace elements could not be detected. Natural and synthetic mineral standards were used for calibration. The oxide forms of elements were calculated by data processing software.

The element mapping was carried out at the University of Szeged, Hungary (Faculty of Science and Informatics, Institute of Chemistry, Department of Applied and Environmental Chemistry), by using a cold field emission Hitachi S4700 electron microscope $(10 \mathrm{kV}$ acceleration voltage, $\times 20-\times 500,000$ magnification, $1.5-1.2 \mathrm{~nm}$ resolution) coupled to a Röntec QX2 energy dispersive X-ray fluorescence spectrometer.

\section{Results}

Petrographic description of the Mócs-01 thin section

The Mócs chondrite corresponds to the L6-type, where shock metamorphosed and recrystallized matrices and several well-distinguished chondrule remnants have been observed (Figs 2-3, 5).

In general the entire Mócs-01 sample has a microgranular and recrystallized texture (Fig. 2). On the basis of the level of recrystallization of the groundmass, the Mócs meteorite was classified as L5-L6 - Miura et al. 1995; Ferko et al. 2000). Chondrules

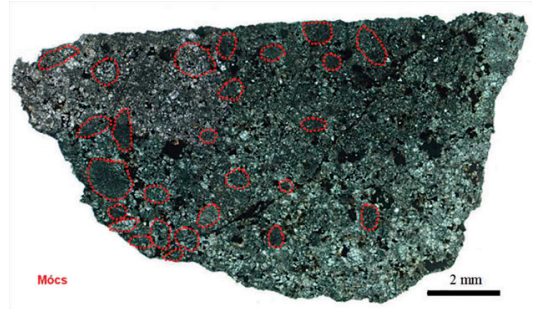

Fig. 2

Chondrules in the Mócs meteorite (dashed line), where 26 chondrules were marked. Most of them have an elongated shape 

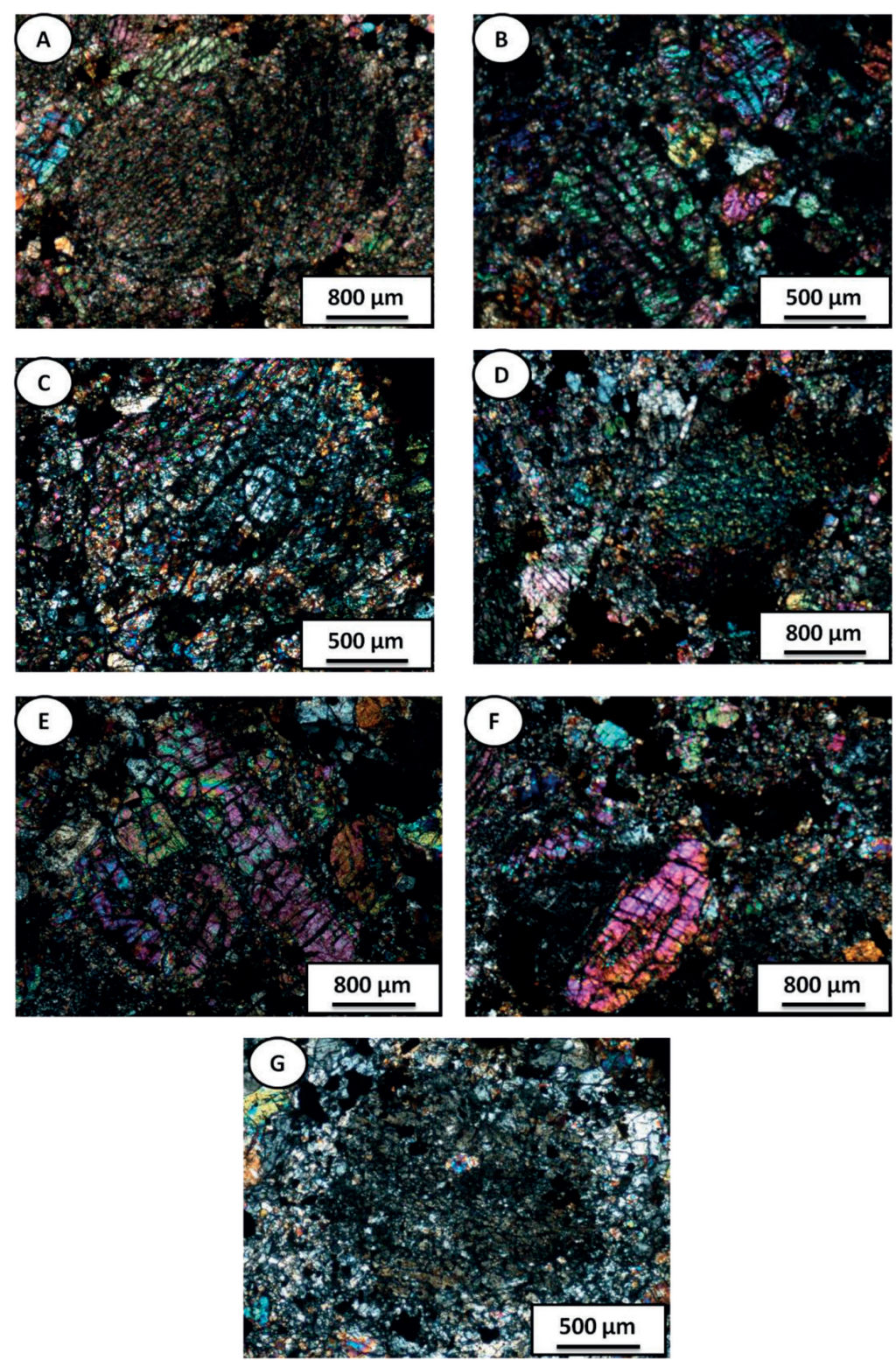

Fig. 3

Photomicrographs of chondrule textures and evidence of shock metamorphism in the Mócs sample, in transmitted light with crossed polars. A: large, radial chondrule. B: Barred chondrule in the neighborhood of poikilitic chondrule fragments. C: recrystallized chondrule. D: recrystallized radial chondrule-fragment in the Mócs meteorite. E: recrystallized porphyritic chondrule. F: elongated granular chondrule in the Mócs meteorite. G: composite chondrule in the Mócs meteorite. The composite chondrule was probably generated by accretion of smaller chondrules 
A
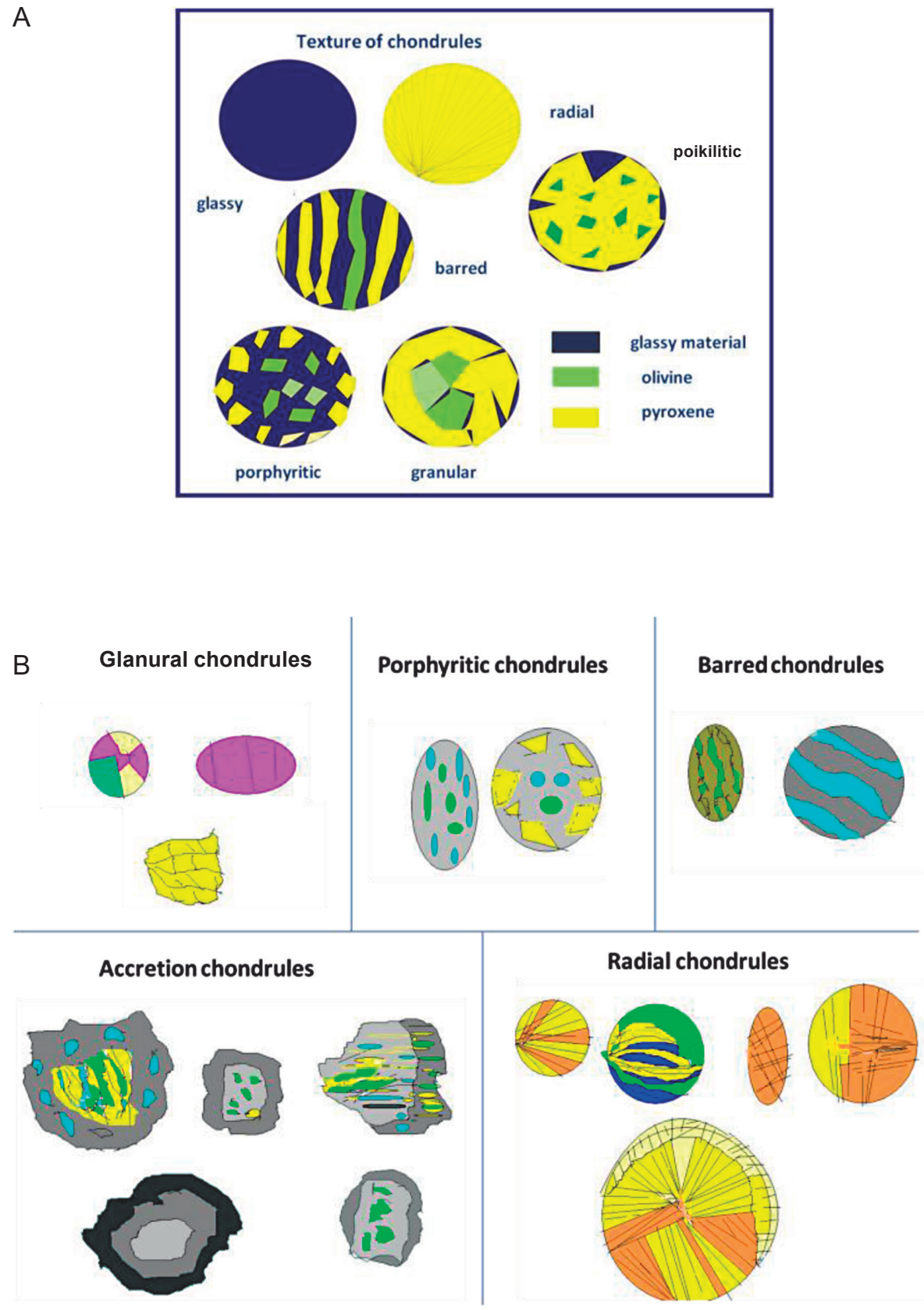

Fig. 4

A: Texture of chondrules. The Mócs meteorite has chondrules with radial and granular textures. B: Observed chondrule textures in the Mócs L6 chondrite 
are relatively rare; they can be recognized by the two following characteristics: (1) spherical outline (Figs 2-3), and (2) orientation. Grain sizes of the groundmass and the chondrules are similar (grain size varies between 30-100 microns due to recrystallization), and the orientation of the grains is mostly random (undulatory extinction of chondrules), except in the case of those grains of chondrules which show well-ordered orientations useful in recognizing and locating chondrules in the sample (Fig. $3 \mathrm{~B}-\mathrm{E}, \mathrm{G})$. It is important to note that the microgranular texture and recrystallization of groundmass indicate signatures of partial melting, which makes the Mócs chondrite a transitional type between L6 and L7.

We observed two principal types of preserved chondrules: (1) elongated granular olivine-chondrules (Fig. 3F) and (2) relatively large, radial chondrules (Fig. 3A). The Mócs-01 sample is vesicular and fractured; both types of chondrule are filled with opaque minerals. In the larger grains there is evidence of strong shock metamorphism, such as occurrence of olivines with mosaic texture and mechanically-twinned pyroxene. For this paper we studied 26 chondrules and elongated chondrule fragments in the Mócs-01 sample, of which 8 are radial, 7 granular, 3 recrystallized glassy, 3 barred, 3 poikilitic, 1 porphyritic and 1 composite (Figs 2-5). In Fig. 2 the 26 chondrules are indicated by marking their outlines with dashed lines.

Of the 26 chondrules, 11 were studied by their images and are shown in more detail. These 11 chondrules (porphyritic chondrule fragments are not counted) are distinguished by their distinctive mineralogy and texture: 2 pieces of recrystallized glassy chondrules ( $1 \mathrm{~mm}$ diameter), 1 granular olivine chondrule, 1 composite chondrule and several porphyritic chondrule fragments (Figs 3 and 4), 3 cases of pyroxene radial chondrules (1-3 mm diameter; Figs 2-5) and 4 cases of olivine porphyritic chondrules (2 mm diameter; Figs 2-5).

The chondrules are described in detail in the order of the estimated assumed cooling rate under which they formed: glassy, radial, barred, porphyritic, poikilitic, and granular (Fig. 4A; Bérczi 2000).

1. Glassy or cryptocrystalline chondrules (similar to afanitic texture in igneous metamorphic rocks). The glassy chondrules in the Mócs-01 thin section have undergone extensive post-shock thermal metamorphism, which induced devitrification of the glass. The devitrified glassy chondrules occur close to shock veins processed by post-shock annealing. The normal thermal metamorphism induced the recrystallization of glassy chondrules far from the shock vein, producing formation crystal nuclei or the complete recrystallization of glassy chondrules to phyllosilicate-microcrystalline feldspar assemblages. It is important to note here that poor preservation of glassy chondrules is common in meteorites of the higher petrologic classes (L5-L6; van Schmus and Wood 1967).

2. Chondrules with radial textures. This chondrule texture type evolved at a lower cooling rate than the glassy chondrules and frequently exhibits dendritic pyroxene crystals along the radial crystallites. Similar to the texture of magmatic rocks, the chondrules show increasing grain size change as a function of in- 

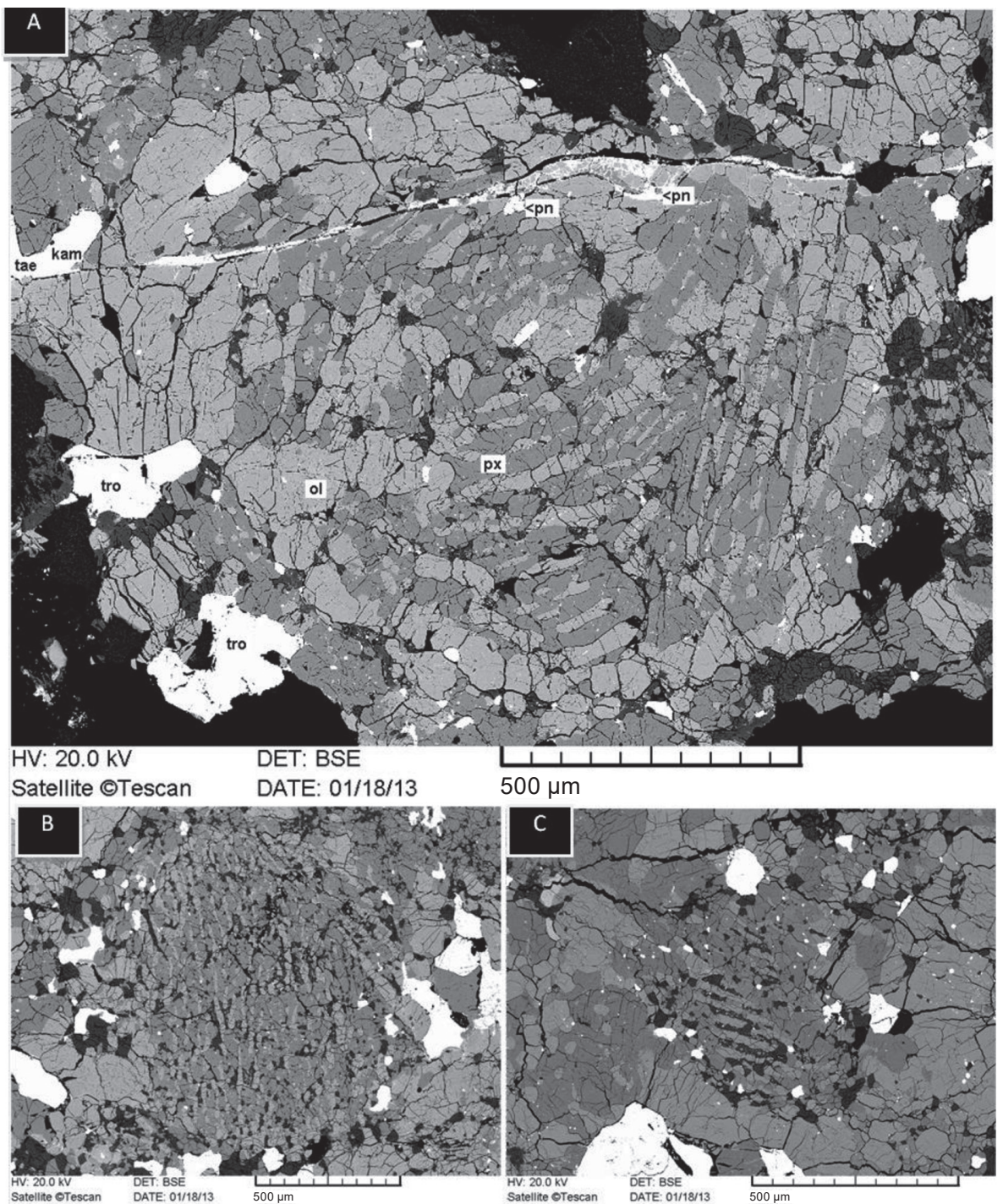

Fig. 5

Radial chondrules in Mócs meteorite - BSE image. The radial chondrule in (A) consists of rimmed opaque minerals such as kamacite (kam), taenite (tae) and troilite (tro). Chondrules are built up from olivine (ol) and pyroxene (px), as well as feldspar (B, C). The largest chondrule is sheared by a shock vein (A), where the vein shows cataclastic texture 
creasing cooling time of the melt droplet. The constituting, needle-like minerals are 10 microns thick and $80-100$ microns long. The radial texture in the chondrules can be divided into two groups:

(a) needle-like crystals growing from a single center (simple radial texture).

(b) needle-like crystals growing from multiple centers in groups (also known as the parquete texture).

In the Mócs-01 thin section only the (a) type texture was observed. However, there are radial chondrules where the radial texture extends to the margin and a radially-textured rim continues growing into the rim at the chondrule surface. This structure of the rim suggests rejuvenation of the crystallization process, beginning at the core and extending to the rim, and a later new crystallization period, which resulted in growth of the extended texture. The crystals which formed in the rim during the later cycle are smaller and thinner.

3. Barred chondrules (long, floating olivine crystals in afanitic mesostasis). In the Mócs-01 thin section these chondrules are made up of olivine and mesostasis, together with lesser pyroxene in the cryptocrystalline rim. The presence of a rim depends on the grade of thermal metamorphic (and aqueous) overprint on the texture.

4. Porphyritic chondrules. These chondrules are generally comprised of olivine or pyroxene or both, and typically have well-crystallized rims. In the cores of these chondrules olivine phenocrysts are observed. These are enclosed by a well-crystallized rim of pyroxene and minor opaque minerals. The presence of opaque minerals in this texture arises from the rotation of the chondrule during the time of crystallization: the grains at the boundary of the chondrules are moved more effectively due to centrifugal force.

The size of the chondrule-forming minerals has been used as a parameter of classification for the thermal metamorphism observed in the chondrules, forming two categories: microporphyritic (10-30 microns) and macroporphyritic (50-80 microns). The microporphyritic type is a secondary texture made up of fine olivine and pyroxene grains that formed due to the recrystallization or mechanical deformation processes of pre-existing granular or macroporphyritic chondrules (van Drongelen et al. 2010). The texture arises from a high postshock cooling rate in the chondrules close to the shock vein.

The macroporphyritic type evolved via a lower cooling rate than that of the microporphyritic type, according to the interpretation of terrestrial magmatic textures. The pre-existing groundmass of chondrules might have been cryptocrystalline or devitrified, as indicated by the needle-shaped pyroxene inclusions within the phenocrysts (Fig. 3F-G).

5. Granular chondrules. The granular chondrules have a granoblastic polygonal/ decussate structure, mostly without mesostasis. Based on the size of the chondrules (based on the observation of 7 granular chondrules), we named them as microgranular (grain size of 10-30 microns) or macrogranular chondrules (grain size of 70-100 microns). The microgranular type formed due to the 
recrystallization of olivine (olivines showing pink-green interference color, straight extinction); the macrogranular type was formed mostly from pyroxenes (minerals showing oblique extinction and yellow interference color).

6. Poikilitic chondrules. In this chondrule type small rounded olivine grains are embedded within larger, polygonal or lath-shaped pyroxenes. The relict groundmass can be seen through the annealed pyroxene grains.

\section{Elemental mapping}

Element mapping was utilized for study of the chemical-mineralogical composition of chondrules close to shock veins.

The Map 1 area contains chromite grains (Fig. 6, Map 1/A), which have been altered to iron oxide via secondary processes. Based on the composite map (Fig. 6, Map 1/B), the shock melt pocket area within the shock vein indicates a composition very close to that of proximal feldspar grains. The melt pocket is enriched in Na compared to its surroundings (Fig. 6, Map 1/C); areas enriched in $\mathrm{K}$ are associated with enrichment of $\mathrm{P}$ and $\mathrm{Ca}$ (Fig. 6, Map 1/D). In contrast to the shock veins, chondrules are composed of more mafic pyroxenes and olivines.

Map 2 shows chromite grains (with high Cr concentration) and troilite (enriched in Fe and $\mathrm{S}$ ), suggesting that oxidation affected those iron oxide-containing phases with relatively high Fe concentration (Fig. 6, Map 2/A). The dark area in the SE of Map 2 is enriched in $\mathrm{Na}$ and $\mathrm{Al}$, which suggests that feldspar was the likely parent mineral of the melt (Fig. 6, Map 2/B). On the Mg-Si-Ca-Fe elemental map (Fig. 6, Map 2/D) the chondrules are easily distinguished by the presence of olivine ( $\mathrm{Mg}-\mathrm{Si}$ ), pyroxene $(\mathrm{Ca}-\mathrm{Si})$, and the opaque $(\mathrm{Fe})$ phases. The chondrule fragments contain olivine, whereas the pyroxenes are concentrated in the groundmass and as crystallites in the adjacent melt phase.

\section{Discussion}

The Mócs chondrite is an L6-type shocked meteorite. In our Mócs-01 sample the thermal metamorphosis and recrystallization effects were studied in the matrix and several chondrules and chondrule remnants. The entire Mócs-01 sample has a generally microgranular and recrystallized texture (Fig. 2). Due to the level of recrystallization the chondrules are relatively rare; they were observed on the basis of their two characteristic features. One was their spherical outline and the second was the orientation of the chondrule-forming minerals.

The higher temperature effects resulting in such textures were described in detail by van Schmus and Wood (1967), Dodd (1969), and Huss et al. (2006). In this process, after obscuring the chondrules, the textural integration of matrix, chondrules, chondrule fragments, and inclusions advances with increasing metamorphic grade. The opaque, fine-grained matrix found in primitive Type 3, ordinary chondrites has 

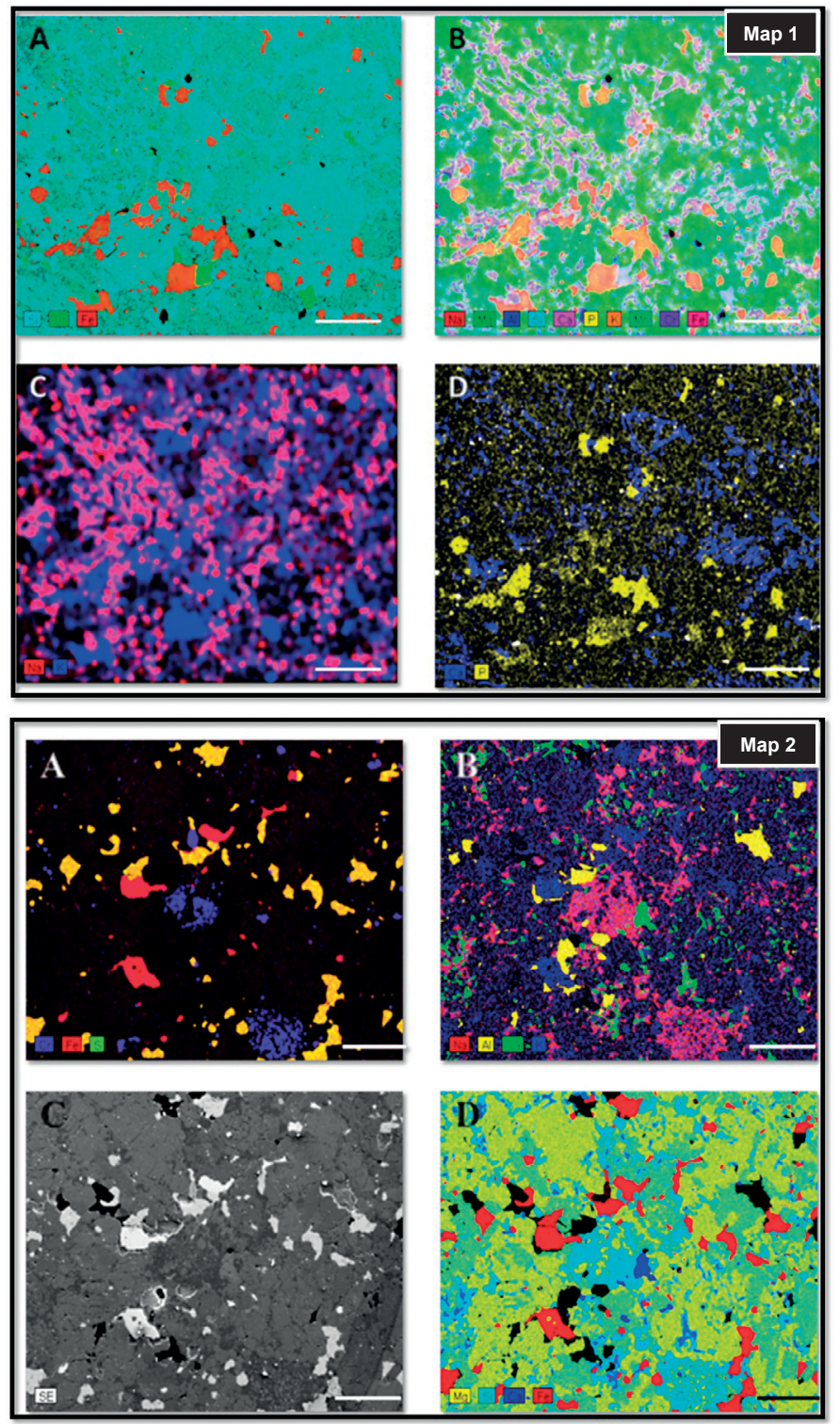

Fig. 6

Map 1: element maps of the upper part of the shock vein (Map 1 in Fig. 1) including chondrule fragments. A: $\mathrm{Si}($ blue $)-\mathrm{Cr}$ (green)-Fe(red), B: composite element map of major elements (Na: red, $\mathrm{Mg}$ : green, $\mathrm{Al}$ : dark blue, Si: light blue, Ca: fuchsia, P: yellow, K: orange, Mn: magenta, Fe: pink and Cr: purple), C: $\mathrm{Na}($ red)-K(blue), D: Ca(blue)-P(yellow), scale: $200 \mu \mathrm{m}$. Map 2: composite element maps of area close to the shock vein (Map 2 area) including mineral and chondrule fragments. A: $\mathrm{Cr}$ (blue)-Fe(red)-S(green), B: $\mathrm{Na}$ (red)-Al(yellow) $-\mathrm{Ca}$ (green)-K(blue), C: secondary electron image, $\mathrm{D}$ : $\mathrm{Mg}$ (yellow)-Si(light blue)-Ca(dark blue)-Fe(red), scale: $200 \mu \mathrm{m}$ 
been almost completely recrystallized by Type 4 , but is still recognizable as matrix. By Type 5, matrix is no longer recognizable and textural integration between chondrules and matrix has begun. In Type 6, small chondrules have lost their identity and only large chondrules are readily recognizable as ghost chondrules. Thermal metamorphism induces not only textural alteration, but the appearance of new phases (van Schmus and Wood 1967). For instance, plagioclase appears only in Alrich chondrules in the case of petrologic Type 3 (Russell et al. 2000). In Type 5 only microcrystalline plagioclase occurs, whereas petrologic Type 6 contains only coarse plagioclase (van Schmus and Wood 1967).

The Mócs meteorite is classified as L6. Plagioclase occurs as tiny grains, and in low abundance in our Mócs-01 thin section sample, where it is concentrated as mineral melt in shock veins and melt pockets (Gyollai et al. in press), or in chondrule mesostases. This phenomenon suggests a lower thermal metamorphic stage (L5.5), which has been overwritten near the veins by post-shock thermal annealing. The grain size of other minerals, such as phosphate, apatite, and chromite increases with progressive thermal metamorphism. In the case of the Mócs-01 thin section, in the shock veins tiny 5-10 micrometer sized chromite grains are embedded in feldspar glass (Gyollai et al. in press), which was formed during post-shock thermal evolution. However, large 200 micrometer-sized chromites were formed later by the effect of increasing thermal metamorphism (Rubin 2003), which is observed near the veins in the Mócs sample. According to Rubin et al. (2001) the grain size of troilite increases with the degree of thermal metamorphism (in cases of Types 5-6 troilite can grow up to about 80-120 microns). Hence the large (100-200 microns) size of the troilite grains suggests that a higher thermal metamorphic grade (Type 6) was reached by the Mócs meteorite. According to our Raman measurements (Gyollai et al. in press) and the BSE element mapping data the pyroxenes in the Mócs meteorite are pure orthoenstatites. Low-calcium clinopyroxene is transformed to orthopyroxene at ca. $\sim 630{ }^{\circ} \mathrm{C}$ (Boyd and England 1965) and thus is largely absent in Types 5 and 6 (van Schmus and Wood 1967).

The appearance of low-Ca clinopyroxene is probably caused by the shock, since it can be formed by shock heating and quenching in chondrites of any petrologic type [stage $\geq S 3$ (Stöffler et al. 1991)]. The melt textures within the shock veins and localized melt pockets in the sample indicate partial melting, and suggest that a high degree of shock and thermal metamorphism affected the Mócs chondrite. The clinopyroxene glass occurs in veins and in melt pockets near veins in the Mócs meteorite (Gyollai et al. in press), and formed by post-shock annealing. Olivine is equilibrated by Type 4, but pyroxene equilibration is not completed until Type 5 (van Schmus and Wood 1967; Dodd 1969). In the most metamorphosed members of Type 6 (classified by some workers as Type 7), the $\mathrm{CaO}$ content of low-Ca pyroxene may be somewhat higher $(>1 \mathrm{wt} \%)$ than in members that have experienced lower peak temperatures (Dodd et al. 1975; Mittlefehldt and Lindstrom 2001). According to our BSE and element mapping data, all pyroxenes and olivines are equilibrated, which suggests petrologic Type 6 for the thermal metamorphism grade of the Mócs chondrite. Since the pyroxenes are pure orthoenstatites, and numerous chondrules occur in our sample, 
it can be concluded that the thermal evolution grade of the Mócs chondrite did not reach the petrologic Type 7. Therefore, it is emplaced between petrographic Types 6 and 7 , providing a transitional Type of 6.5 .

\section{Conclusion}

The Mócs L6 chondrite has been affected by two types of thermal transformations. One was the regular metamorphism of ordinary chondrites reaching the L6 grade; the second was the impact generated post-shock heating. The shock heating effects can be observed in the pyroxenes and feldspars of the chondrite texture of the Mócs01 thin section sample. The shock veins and melt inclusions crosscut the matrix and close to the veins several pyroxene melt glasses are observed, which indicate a peak temperature of the shock heating up of $1100^{\circ} \mathrm{C}$. This is far higher than the regular L6 heating temperature of $750-850^{\circ} \mathrm{C}$. Feldspar melt pockets with chromite inclusions also occur in the vicinity of the shock veins, suggesting that a high rate of shock and thermal metamorphism affected the Mócs chondrite. On the basis of the accumulated heat effects, we propose to classify Mócs meteorite as Mócs L6.5 chondrite.

\section{References}

Bérczi, Sz. 2000: Kis atlasz a Naprendszerről (1): Planetáris és anyagtérképek a holdkőzetekröl és meteoritekröl (Concise atlas of the Solar System: Planetary and material mapping of the lunar rocks and meteorites). - Budapest, Hungary. (in Hungarian)

Bérczi, Sz., S. Józsa, Zs. Kovács, B. Lukács, Gy. Szakmány 2004: Studies of thermal evolution of a chondritic asteroidal body: Synthesis from Antarctic meteorite thin section set of the National Institute of Polar Research, Tokyo. - Acta Mineralogica Petrographica, 45/2, pp. 55-60.

Boyd, F.R., J.L. England 1965: The rhombic enstatite-clinoenstatite inversion. - Carnegie Institution of Washington Year Book, 64, pp. 117-120.

Dodd, R.T. 1969: Metamorphism of the ordinary chondrites: A review. - Geochimica et Cosmochimica Acta, 33, pp. 161-203.

Dodd, R.T., J.E. Grover, G.E. Brown 1975: Pyroxenes in the Shaw (L-7) chondrite. - Geochimica et Cosmochimica Acta, 39, pp. 1585-1594.

Ferko, T.E., L. Schultz, L. Franke, D.D. Bogard, D.H. Garrison, R. Hutchison, M.E. Lipschutz 2000: Exposure history of the Mócs (L6) chondrite: A study of strewn field samples. - Meteoritics and Planetary Science, 35/6, pp. 1215-1227.

Greenwood, R.C., B. Schmitz, J.C. Bridges, R. Hutchison, I.A. Franchi 2007: Disruption of the L chondrite parent body: New oxygen isotope evidence from Ordovician relict chromite grains. - Earth and Planetary Science Letters, 262/1-2, pp. 204-213.

Gyollai, I., K. Fintor, Sz. Nagy, Sz. Bérczi, A. Gucsik, M. Veres in press: Characteristic shock-induced microstructures in Mócs meteorite (L6) revealed by Micro-Raman Spectroscopy. - Planetary and Space Science.

Haack, H., P. Farinella, E.R. Scott, K. Keil 1996: Meteorite, asteroidal, and theoretical constraints on the 500-Ma disruption of the L chondrite parent body. - Icarus, 119, pp. 182-191.

Huss, G.R., A.E. Rubin, J.N. Grossman 2006: Thermal Metamorphism in Chondrites. - In: Lauretta, D.S., H.Y. McSween Jr. (Eds): Meteorites and the Early Solar System II (Space Science Series), University of Arizona Press, Tucson, pp. 565-586. 
Korochantseva, E.V., M. Trieloff, C.A. Lorenz, A.I. Buykin, M.A. Ivanova, W.H. Schwarz, E.K. Jessberger 2007: L-chondrite asteroid breakup tied to Ordovician meteorite shower by multiple isochron 40Ar-39Ar dating. - Meteoritics and Planetary Science, 42, pp. 113-130.

Kubovics, I., B. Lukács, Sz. Bérczi, K. Gál-Sólymos, A. Kiss, G. Albert, B. Gellért, Cs. Detre 1997: Iron grain size distribution in an L sequence of chondrites from Hungary: Mezömadaras (L3), Knyahinya (L5) and Mócs (L6). - TISS Conference Abstracts, Tokyo, pp. 13-14.

Kubovics, I., Z. Ditrói-Puskás, K. Gál-Sólymos 2004: Re-evolution of meteorites from the Carpathian Basin: Preliminary results from Kisvarsány, Knyahinya, Mezőmadaras, Mike, Mócs and Nyírábrány. - Acta Geologica Hungarica, 47/2-3, pp. 269-285.

Mittlefehldt, D.W., M.M. Lindstrom 2001: Petrology and geochemistry of Patuxent Range 91501, a clast-poor impact melt from the L-chondrite parent body and Lewis Cliff 88663, an L7 chondrite. Meteoritics and Planetary Science, 36, pp. 439-457.

Miura, Y., G.O. Iancu, G. Iancu, K. Yanai, H. Haramura 1995: Reexamination of Mocs and Tauti chondritic meteorites: classification with shock degree. - Proceedings of NIPR Symposium on Antarctic Meteorites, 8, pp. 153-166

Nesvorný, D., A. Morbidelli, D. Vokrouhlický, W.F. Bottke, M. Brož 2002: The Flora family: A case of the dynamically dispersed collisional swarm? - Icarus, 157, pp. 155-172.

Nesvorný, D., D. Vokrouhlický, A. Morbidelli, W.F. Bottke 2009: Asteroidal source of L chondrite meteorites. - Icarus, 200/2, pp. 698-701.

Rubin, A.E. 2003: Chromite-plagioclase assemblages as a new shock indicator; implications for the shock and thermal histories of ordinary chondrites. - Geochimica et Cosmochimica Acta, 67, pp. 2695-2709.

Rubin, A.E., F. Ulff-Møller, J.T. Wasson, W.D. Carlson 2001: The Portales Valley meteorite breccia: Evidence for impact-induced melting and metamorphism of an ordinary chondrite. - Geochimica et Cosmochimica Acta, 65, 323-342.

Russell, S.S., G.J. MacPherson, L.A. Leshin, K.D. McKeegan 2000: 16 O enrichments in aluminum-rich chondrules from ordinary chondrites. - Earth and Planetary Science Letters, 184, pp. 57-74.

Stöffler, D., K. Keil, E.R.D. Scott 1991: Shock metamorphism of ordinary chondrites. - Geochimica et Cosmochica Acta, 55, pp. 3845-3867.

van Drongelen, K., K. Tait, G. Clark, P. McCausland 2010: Petrographic and geochemical analysis of the Shelburne meteorite, an L5 ordinary-chondrite fall. - Journal of the Royal Astronomical Society of Canada, 104/4, $132 \mathrm{p}$.

van Schmus, W.R., J.A. Wood, 1967: A chemical-petrologic classification for the chondritic meteorites. - Geochimica et Cosmochimica Acta, 31, pp. 747-765.

Xie, X., M. Chen, C. Dai, A. El Goresy 2000: Characteristics in naturally and experimentally shocked chondrites: A clue to PT conditions of impacted asteroids. - Science in China, Series D: Earth Sciences, 43/5, pp. 480-486. 